Uluslararası Mühendislik

Cilt/Volume:11 Sayı/Issue:1 Ocak/January 2019

Araştırma Makalesi / Research Article

\title{
Mathematical Modeling and Simulation of Full Flight Helicopter Simulator
}

\author{
M. Taylan Das*1 ${ }^{* 1}$, Ismail Kumpas ${ }^{2}$ \\ ${ }^{1}$ Kirlkkale Üniversite Ankara Yolu 7. Km,71450, Kirikkale, TURKEY \\ ${ }^{2}$ Vestel Savunma, 06935 Ankara, TURKEY
}

\begin{abstract}
In Aviation, Flight simulators are highly technological devices which are especially used to create the highly-accurate and zerorisk training environment for orientation, emergency, refresher, combat readiness \& maintenance / testing pilot training. Full Flight Simulators are the simulators including a cockpit exactly like the real cockpit, visual system which is very close adapting the outside world images, a main simulation software which simulates the aerodynamic flight performance and the disruptive effects of helicopter. In this study, mathematical modelling of AS-532 Cougar helicopter is performed by using Newton-Euler equation. Matlab-Simulink is used for demonstration of simulation results. Comparison of real simulator values and simulation results are enclosed.
\end{abstract}

\section{Key Words}

"Mathematical Modelling, Simulation, Full Flight Simulator" 


\section{INTRODUCTION}

The aviation industry has correlated with simulation more than any other safety-critical industry. While simulators are still used for stick-and-rudder and instrument training, today they are also part of practically all aspects of aviation training and further the new multi-crew pilot license (MPL) rests almost entirely on simulated flight training. The investment in simulation for aviation industry ensures industry-wide confidence that it can save time, money and lives, in addition to provide effective training.

The importance of pilot flight training simulators is increasing day by day for military use as well as civil use. Nowadays, the importance of Simulator is increasing on both Military and Civilian Pilot Trainings. Simulator provides for excellent flexibility in training of normal, abnormal, and emergency procedures as well as flight maneuvers for initial training, recurrent training and type rating certification.

Flight simulators plays a critical role in modern aviation training and gives perfect opportunity to the pilots training with realistic flight instruments with realistic malfunctions. Flight simulators help new pilots to prepare real flights and gain experience on flight controls and help experienced pilots to refresh their flight procedures. In addition, pilots can try several malfunctions safely and low-cost that cannot be tested or difficult to try but possible to occur on real flight (ICAO,2014).

Flights hours on modern simulators are considered actual flight hours cause of feeling almost all effects on aircraft. So that the actual flight hours revised in pilot flight trainings and some of these hours are applied on simulators. For instance; Turkish Air Force (TURAF) revised initial flight training on training aircraft (before fighting aircraft). Normally new pilot needed 85 actual flight sorties to get the flight certification or flight license. While TURAF had added to train on simulator in initial flight training new pilot needs 69 actual flight sortie and the remaining's are on 10 modern simulators (that are developed and produced by HAVELSAN) for getting the flight certification. The training is applied in this situation nearly one year and 30.000 hours' simulator training is used. This training increases the effectiveness and safety of flight trainings are observed (Dahlstrom, $\mathrm{N}$ et al., 2009).

Simulator trainings provide especially for new pilots to improve readiness of cognitive situations and train behaviors what to do during unexpected cases. Because simulator trainings provide flexibility in training of normal, abnormal, and emergency procedures as well as flight maneuvers for pilots that they cannot try or having great risk to try them during actual flight. Therefore; to decrease the risk of any accident, simulator training is more safe, effective and economic training method (MSI, 2015).

Literature review is achieved for types of simulators and understanding of full flight simulator. Then, Modeling and disruptive effects are described. Simulation results are compared with real simulator data. Especially used simulator which is designed with high technology and modeled of the dynamic effects and simulation of the real aircraft is described detailed. In addition to known disruptive effects which are widely used by commercial simulators, AS 532 Cougar Helicopter simulator designed by Havelsan has 9 types and 271 malfunctions/disruptive effects (420 if sub-malfunctions included).

\subsection{Flight Simulators}

The flight simulator is a system that tries to simulate as closely as possible and in a realistic manner while in the experience of actual flight. Flight simulators have great wide-concept from computer games to Full Mission / Full Flight Simulators that can be controlled by advanced computer technology and have an exact same cockpit mounted on the hydraulic or electromechanical actuators (Havelsan, 2007).

Flight simulation can be defined as a representation of the dynamic characteristics of vehicles and systems that have different realities with the purpose of research, design, development, training or entertainment. Flight simulation should be real time during training. Real time means all temporal relationship on simulator should be same as on aircraft. For instance; weather situation, terrain situation, aerodynamics effects, sound effects on simulator should be same as on real aircraft.

Flight simulators used especially for type-rating training in civil aviation. It is also widely used for refreshment training. Federal Aviation Administration (FAA) approves all type-rating training on the simulator if the simulator meets the requirements of Airplane Simulator Qualification AC120-40C published by FAA. Same as FAA, the other authority European Aviation Safety Agency (EASA) also accepts all type-rating training on the simulator if the simulator has the certification of JAR-FSTD-A (for airplane) or JAR-FSTD-H (for helicopter) published by EASA. Regarding to this certification, there are four levels (A-B-C-D) per maturity and realistic level. Level D is the highest full flight simulator qualification. If the simulator has Level D certification, it means this is equipped with high technological systems.

\subsection{Full Flight Simulators (FFS)}

Full Flight Simulators (FFS) are the simulators comprising many sub-systems such as; a cockpit exactly like the real helicopter / aircraft cockpit, a high-fidelity visual system which is very close adapting the outside world images, a main simulation software which simulates the aerodynamic model and the behavior of the flight system of helicopter / aircraft, 6-axis motion system (6 DOF motion system) and control loading system which provide accurate physical sensations. (Havelsan, 2007) The pilot can interact with the simulator in real time since the simulation software is in real time. All displays which are generated by very complicated computers called Image Generators (IG) are an almost real world that you cannot recognize you are in the simulator. All 
instruments, avionics and hardware in the cockpit are real or simulated equipment. All sound effects and communications are simulated.

In the full flight simulator, the pilot can observe the velocity, altitude of the aircraft in the cockpit instruments. Orientation changes can be observed in the visual system and seen again in cockpit indicators. Calculated accelerations and changes in these calculated values are felt by the help of the motion system. Control loading system provides pilots accurate force feedback of flight controls. High-frequency vibration effects are given to the pilot via vibration system. The aircraft position on the earth can be exactly observed from navigation instruments. It means that pilots can feel all aircraft effects on a full flight simulator. (Wikipedia,2016)

The Eurocopter AS-532 Cougar is a twin-engine, medium-weight, multi-purpose helicopter shown in Figure 1(a). All tests for this study were realized in the full flight simulator of AS-532 Cougar Helicopter Platform having Level-D certification shown in Figure 1(b).

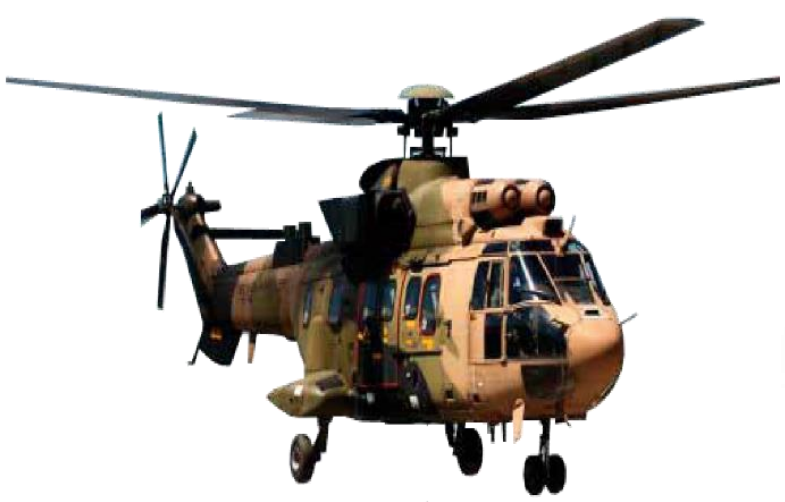

(a)

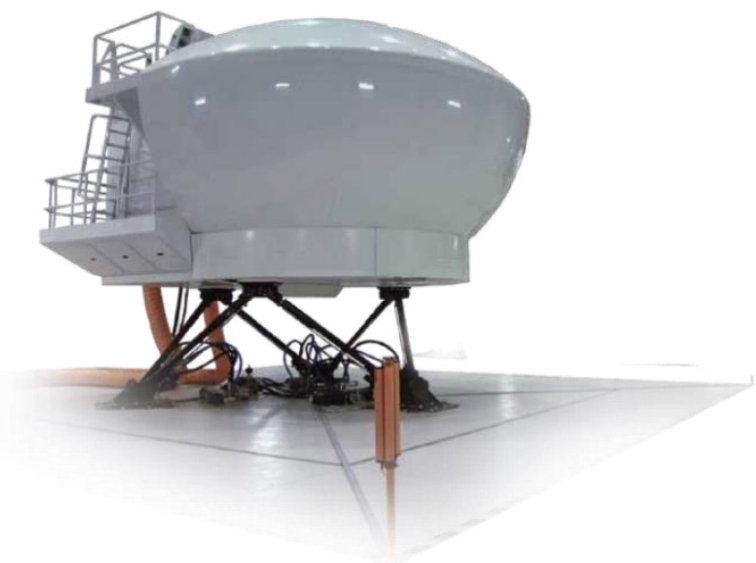

(b)

Figure 1 (a) AS-532 Cougar Helicopter, (b)AS-532 Cougar Helicopter Full Flight Simulator

\section{SIMULATION AND MODELLING}

\subsection{Simulator Specifications}

This full flight simulator has been designed and manufactured in order to create the highly-accurate and zero-risk training environment for orientation, emergency, refresher, combat readiness \& maintenance / testing pilot training of AS-532 Cougar helicopter pilots. It is designed in HAVELSAN, one of Turkish Defense Company. Providing experience and capabilities required for each pilot can be achieved with the most realistic training at six-axis motion platform using an unlimited variety of scenarios with effects created by the computer by using realistic three-dimensional modeling of the AS-532 Cougar flight missions in the simulator environment. The full flight simulator of Cougar helicopter basically includes main software simulation, instructor operation station, input/output (I/O) system, visual system, motion system, control loading system, sound system and vibration system. All related software and hardware work compatible with each other.

The main software contains high-fidelity helicopter flight and mission subsystems models. The core of the flight-related subsystems is six-DOF (Degree of Freedom) flight dynamics modeling with rigid body assumption. The translational and rotational equations of motion are derived by using Newton-Euler Law. These calculations support the all mission profile phases. These phases are taxi, take-off, IGE (In Ground Effect) hover, OGE (Out of Ground Effect) hover, low and high-speed cruise, climb, descent, vertical climb, auto-rotation, and landing. In addition, detailed Stability Augmentation System (SAS) and Automatic Flight Control System (AFCS) modeling are performed. High-fidelity aerodynamic modeling for main rotor, tail rotor, and fuselage is realized. Detailed engine and transmission system modeling are included. Other flight related subsystems physical models such as electrics, hydraulics, and fuel system are included. Similarly, related sensor and navigation models are realized.

In brief, simulator has technical specifications as; JAR Level D qualification in international (EASA) standards; Six-Axis hydraulic motion system; Three-axis vibration platform, $220^{\circ}$ horizontal x $60^{\circ}$ vertical visual system, 5-Channel image generator and projectors.

In order to support the pilot training, there are approximately 271 (if sub-malfunctions included it will be approximately 420) defined malfunctions available in the Cougar helicopter flight simulator. Malfunctions are identified for different subsystems such as engine, electrics, hydraulics, fuel, sensor \& navigation and automatic flight control system.

The main training capabilities of simulator are Cockpit Procedures; Engine Start-Up, Taxi Controls and Taxiing, Landing, Takeoff, Normal and Emergency Procedures; Engine Stop and Rotor Stop, Search \& Rescue Training. Figure 2 demonstrates the cockpit view of helicopter. 


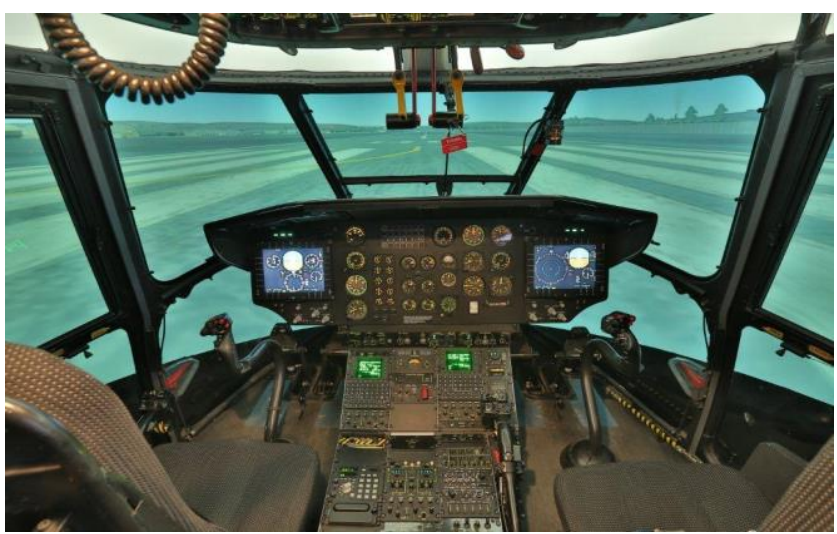

Figure 2. AS-532 Cougar Helicopter Full Flight Simulator Cockpit View

\subsection{Mathematical Model}

The mathematical modeling of the helicopter flight dynamics is built-up by using superimposing the component effects. The forces and moments that are affecting on the related component such as the main rotor, tail rotor, fuselage, propulsive subsystem, and landing gear subsystem are calculated and then these calculated forces and moments are transported to the center of gravity of the helicopter. The equations of motions including translational and rotational manner are derived. Acceleration, velocity and position equations of the helicopter are obtained. During this calculation, the effect of altitude, air pressure and temperature change are also included into model. Ground effect is added in the aerodynamic calculations especially in the hover modeling. The helicopter and surface type interactions are taken into account during taxi, take-off and landing phases. The force and moment equations in body axis system (shown in Figure 3) can be given as follows;

$$
\begin{array}{ll}
\text { Force Equations } & : \vec{F}=\left.m \cdot \frac{d \vec{v}}{d t}\right|_{B}+m \cdot \vec{\omega} \times \vec{V} \\
\text { Moment Equations } & : \vec{M}=\left.\frac{d \vec{H}}{d t}\right|_{B}+\vec{\omega} \times \vec{H}, \vec{H}=I \vec{\omega}_{E}
\end{array}
$$

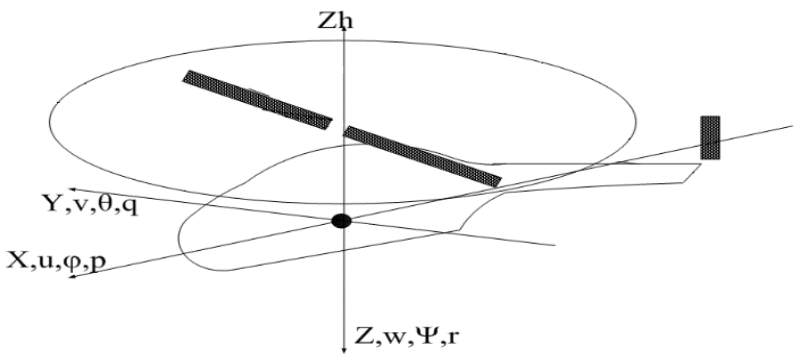

Figure 3. Body Axis System Representation

Where $\mathrm{F}$ is the total force vector, $\mathrm{M}$ is the total moment vector. The force components in the body axis system are $\mathrm{X}$, $\mathrm{Y}, \mathrm{Z}$; and moment components in body system axis are L, M, N. Translational velocity components are $\mathrm{u}$, v, w; and rotational velocity components are p, q, r. The helicopter mass is $\mathrm{m}$ and $\vec{\omega}$ the angular velocity, $\overrightarrow{\mathrm{V}}$ the translational velocity, $\overrightarrow{\mathrm{H}}$ the angular momentum and I represented as the inertia matrix. Euler angles $\phi, \theta, \psi$ represent roll, pitch, and yaw respectively. Subscript B refers to body axis system, subscript E refers to Earth-Fixed axis system.

$$
\left[\begin{array}{c}
X \\
Y \\
Z
\end{array}\right]=m\left[\begin{array}{c}
\dot{u} \\
\dot{v} \\
\dot{w}
\end{array}\right]+m \cdot \operatorname{det}\left[\begin{array}{ccc}
\vec{\imath} & \vec{\jmath} & \vec{k} \\
p & q & r \\
u & v & w
\end{array}\right]
$$

Then, by re-arranging the equations;

$$
\begin{aligned}
& \dot{\mathrm{u}}=\frac{\mathrm{x}}{\mathrm{m}}+\mathrm{rv}-\mathrm{qw} \\
& \dot{\mathrm{v}}=\frac{\mathrm{y}}{\mathrm{m}}-\mathrm{ru}+\mathrm{pw} \\
& \dot{\mathrm{w}}=\frac{\mathrm{z}}{\mathrm{m}}+\mathrm{qu}-\mathrm{pv}
\end{aligned}
$$

When Eq. 4 (Tichon, J.G et al.,2014), (Etkin, B. \& Reid, L.D., 1996) is integrated, translational velocity components in body axis are obtained. Then, by performing a transformation to earth-fixed axis system and integrating, the positions are calculated in the earth-fixed axis systems.

Similarly, moment equations are given as follows; 


$$
\left[\begin{array}{c}
\mathrm{L} \\
\mathrm{M} \\
\mathrm{N}
\end{array}\right]=\left[\begin{array}{ccc}
\mathrm{I}_{\mathrm{xx}} & -\mathrm{I}_{\mathrm{xy}} & -\mathrm{I}_{\mathrm{xz}} \\
-\mathrm{I}_{\mathrm{xy}} & \mathrm{I}_{\mathrm{yy}} & -\mathrm{I}_{\mathrm{yz}} \\
-\mathrm{I}_{\mathrm{xz}} & -\mathrm{I}_{\mathrm{yz}} & \mathrm{I}_{\mathrm{zz}}
\end{array}\right]\left[\begin{array}{c}
\dot{p} \\
\dot{\mathrm{q}} \\
\dot{\mathrm{r}}
\end{array}\right]+\overrightarrow{\omega x}\left[\begin{array}{ccc}
\mathrm{I}_{\mathrm{xx}} & -\mathrm{I}_{\mathrm{xy}} & -\mathrm{I}_{\mathrm{xz}} \\
-\mathrm{I}_{\mathrm{xy}} & \mathrm{I}_{\mathrm{yy}} & -\mathrm{I}_{\mathrm{yz}} \\
-\mathrm{I}_{\mathrm{xz}} & -\mathrm{I}_{\mathrm{yz}} & \mathrm{I}_{\mathrm{zz}}
\end{array}\right]\left[\begin{array}{l}
\mathrm{p} \\
\mathrm{q} \\
\mathrm{r}
\end{array}\right]
$$

Then, by re-arranging the Eq. 5 (Tichon, J.G et al.,2014), (Etkin, B. \& Reid, L.D., 1996) and assuming $\mathrm{I}_{\mathrm{xy}}=0$ and $\mathrm{I}_{\mathrm{yz}}=0$ since exact values are small,

$\dot{\mathrm{p}}=\left(\mathrm{I}_{\mathrm{xz}}\left[\mathrm{I}_{\mathrm{xx}}-\mathrm{I}_{\mathrm{yy}}+\mathrm{I}_{\mathrm{zz}}\right] \mathrm{pq}-\left[\mathrm{I}_{\mathrm{zz}}\left(\mathrm{I}_{\mathrm{zz}}-\mathrm{I}_{\mathrm{yy}}\right)+\mathrm{I}_{\mathrm{xz}}{ }^{2}\right] \mathrm{qr}+\mathrm{I}_{\mathrm{zz}} \mathrm{L}+\mathrm{I}_{\mathrm{xz}} \mathrm{N}\right) /\left(\mathrm{I}_{\mathrm{xx}} \mathrm{I}_{\mathrm{zz}}-\mathrm{I}_{\mathrm{xz}}{ }^{2}\right)$

$\dot{\mathrm{q}}=\frac{1}{\mathrm{I}_{\mathrm{yy}}}\left[\left(\mathrm{I}_{\mathrm{zz}}-\mathrm{I}_{\mathrm{xx}}\right) \mathrm{pr}-\mathrm{I}_{\mathrm{xz}}\left(\mathrm{p}^{2}-\mathrm{r}^{2}\right)+\mathrm{M}\right]$

$\dot{\mathrm{r}}=\left(\left[\left(\mathrm{I}_{\mathrm{xx}}-\mathrm{I}_{\mathrm{yy}}\right) \mathrm{I}_{\mathrm{xx}}+\mathrm{I}_{\mathrm{xz}}{ }^{2}\right] \mathrm{pq}-\mathrm{I}_{\mathrm{xz}}\left[\mathrm{I}_{\mathrm{xx}}-\mathrm{I}_{\mathrm{yy}}+\mathrm{I}_{\mathrm{zz}}\right] \mathrm{qr}+\mathrm{I}_{\mathrm{xz}} \mathrm{L}+\mathrm{I}_{\mathrm{xx}} \mathrm{N}\right) /\left(\mathrm{I}_{\mathrm{xx}} \mathrm{I}_{\mathrm{zz}}-\mathrm{I}_{\mathrm{xz}}{ }^{2}\right)$

Angular velocity components in body axis are obtained by integrating Eq 6. Euler orientation angles are determined by integrating Eq. 7, (McCormick, B. W. ,1995). Simulator was modelled according to these assumptions and derivations.

$\dot{\phi}=\mathrm{p}+\sin \phi \tan \theta \mathrm{q}+\cos \phi \tan \theta \mathrm{r}$

$\dot{\theta}=\quad \cos \phi \mathrm{q}-\sin \phi \mathrm{r}$

$\dot{\psi}=\sin \phi \sec \theta \mathrm{q}+\cos \phi \sec \theta \mathrm{r}$

Cougar Simulator (Force Effects) QTG Test Results and the comparison of static and dynamic forces between the aircraft and simulator data are illustrated in Figures 4 and 5 respectively. In Figure 6, longitudinal response is compared for aircraft data (blue line) and simulator data (pink dashed line). Results are nearly same on longitudinal response for cyclic motion. The simulator data are between the tolerance rates.

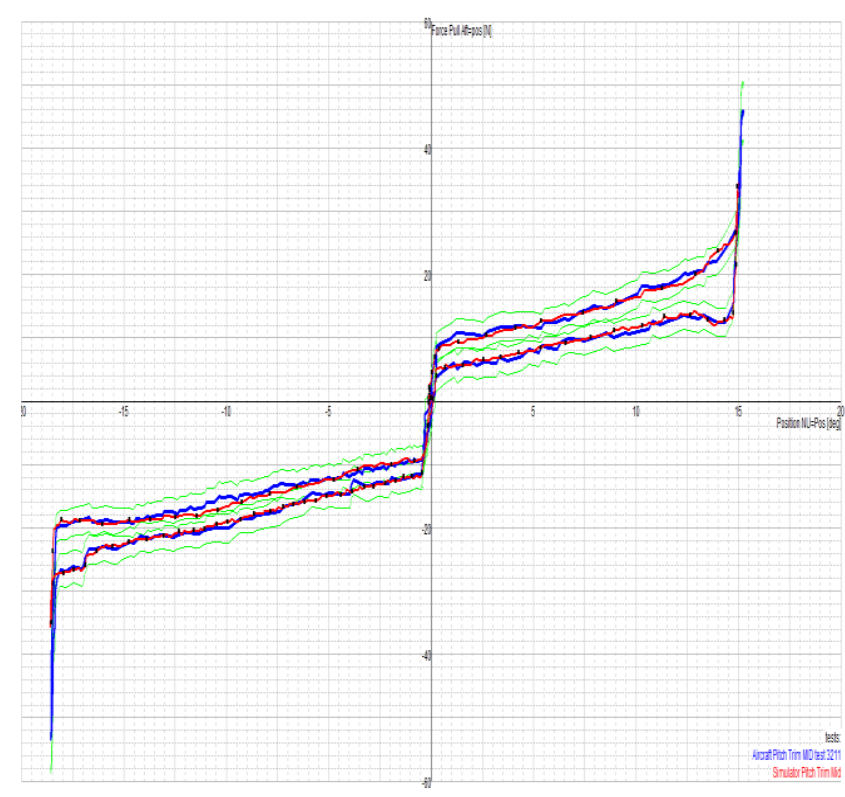

a) Pitch Static Trim Mid - Hydr Sys On

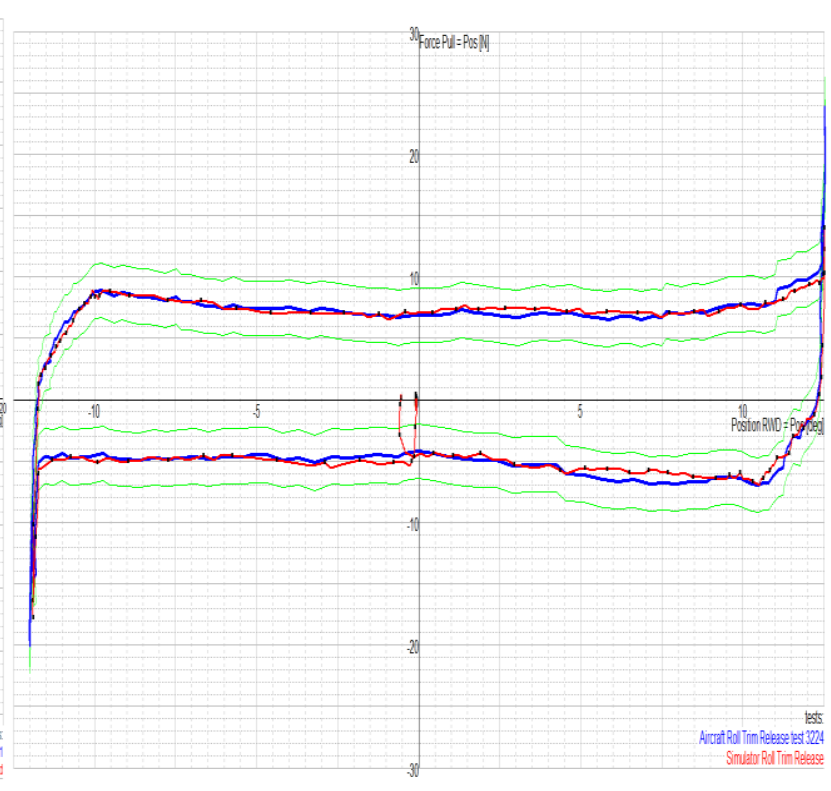

b) Roll Static Trim Off/Release - Hydr Sys On Figure 4. (a), (b) Comparison of Simulation and simulator static trim behavior

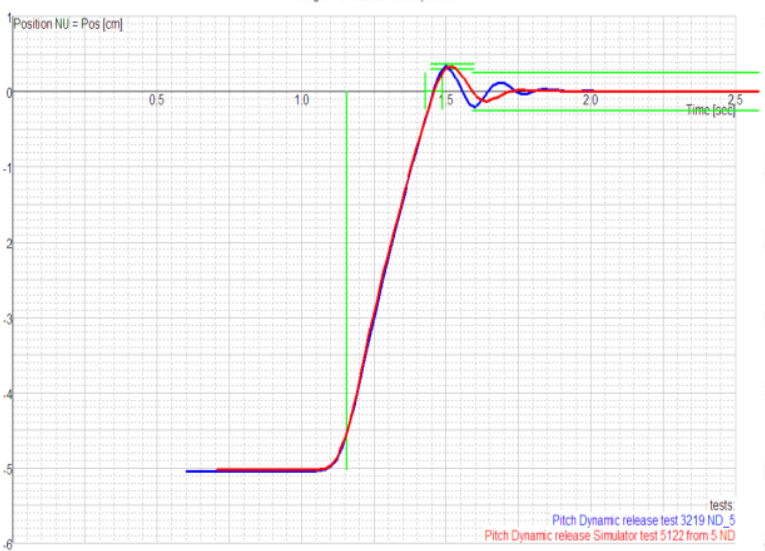

a) Pitch Dynamic Test Stick Normal from Forward

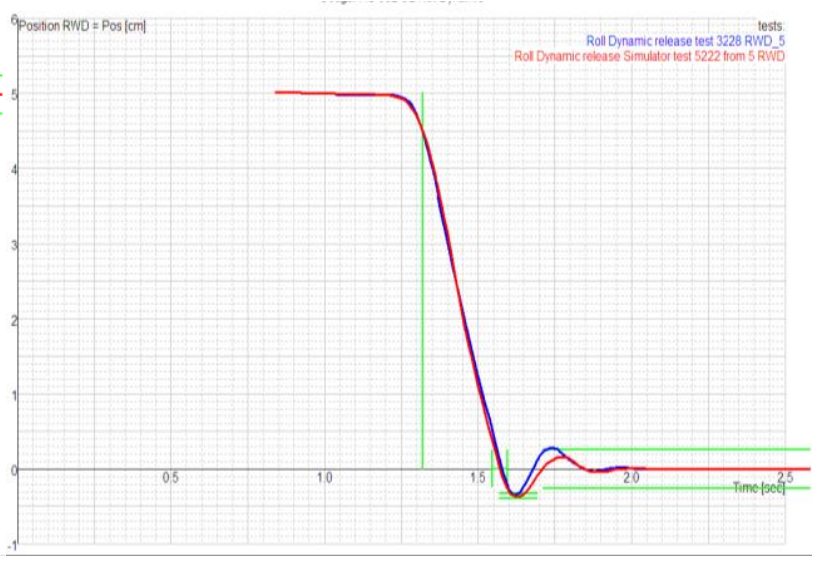

b) Roll Dynamic Test Stick Normal from Right

Figure 5. (a) and (b) Simulator dynamic behavior for Pitch and Roll motion. 

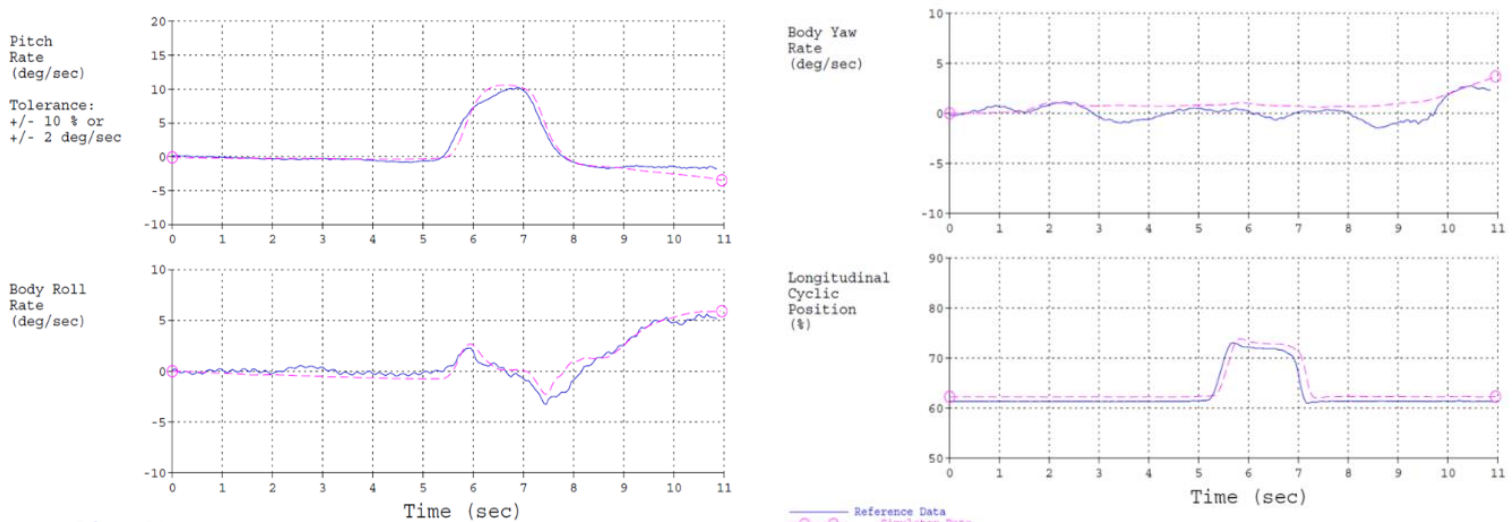

Figure 6. Cougar Simulator Longitudinal Response QTG Test Results for Pitch, Roll and Yaw

\section{CONCLUSION}

Generally, simulator improves the training level of the pilots. It helps intermediate and advanced level pilots to improve their technical skills, wheras it helps beginner level pilots to increase awareness related to flight training. In this study, Mathematical modelling of AS-532 Cougar helicopter is represented by using Newton-Euler equation. Simulation and application results are compared. Results shows that this simulator can respond like a real helicopter. Comparison of real simulator values and simulation results are enclosed.

\section{REFERENCES}

Dahlstrom, N., Dekker, S., Van Winsen, R., \& Nyce, J., Fidelity and validity of simulator training. Theoretical Issues in Ergonomics Science, 10(4), 305-314, 2009.

Etkin, B. \& Reid, L.D., Dynamics of Flight - Stability and Control, Third Edition, John Wiley \& Sons, Inc, 1996. MSI. (2015). http://www.milscint.com/tr/simulator-egitim-merkezi-kazandirdi/.

Full flight simulator, In Wikipedia, The Free Encyclopedia. Retrieved 07:55, March 12, 2017, from https://en.wikipedia.org/w/index.php?title=Full_flight_simulator\&oldid=702545713

Havelsan Simulator Orientation Document, 2007.

McCormick, B. W., Aerodynamics, Aeronautics and Flight Mechanics, Second Edition, John Wiley \& Sons, Inc, 1995.
ICAO.
(2014).
Safety
Report.
International
Civil
Aviation

http://www.icao.int/safety/Documents/ICAO_2014\%20Safety\%20Report_final_02042014_web.pdf

Tichon, J.G., Wallis, G., Riek, S. \& Mavin, T.. Physiological measurement of anxiety to evaluate performance in simulation training. Cogn Tech Work, 2014. 